\title{
Biomaterials
}

\section{Thermal decomposition and reconstitution of hydroxyapatite in air atmosphere}

\author{
Chun-Jen Liao ${ }^{\text {a }}$, Feng-Huei Lin ${ }^{\mathrm{a}, *}$, Ko-Shao Chen ${ }^{\mathrm{b}}$, Jui-Sheng Sun ${ }^{\mathrm{c}}$ \\ ${ }^{a}$ Institute of Biomedical Engineering, College of Medicine, National Taiwan University, Taipei, Taiwan, ROC \\ ${ }^{\mathrm{b}}$ Department of Orthopaedic Surgery, College of Medicine, National Taiwan University, Taipei, Taiwan, ROC \\ ${ }^{\mathrm{c}}$ Department of Material Engineering, Tatung Institute of Technology, Taipei, Taiwan, ROC
}

Received 10 October 1998; accepted 10 April 1999

\begin{abstract}
In this paper, the decomposition and reconstruction behavior of hydroxyapatite (HAP) during heating and cooling in air atmosphere were studied. The commercial HAP were chosen and gradually heated to $1500^{\circ} \mathrm{C}$ and cooled to room temperature by a program controlled $\mathrm{SiC}$ heated furnace. X-ray diffraction (XRD) and Fourier-transformed infrared (FTIR) analysis were used to investigate the change of crystalline phases and functional groups of HAP at different temperatures. Weight change of samples was recorded by thermogravimetric analysis (TGA) during heating and cooling. The results revealed that HAP gradually releases its $\mathrm{OH}^{-}$ ions and transforms into OHAP in the temperature of $1000-1360^{\circ} \mathrm{C}$. Above $1360^{\circ} \mathrm{C}$, the OHAP would decompose into TTCP and $\alpha \mathrm{TCP}$ phase. The $\mathrm{OH}^{-}$stretching bands of HAP could be traced by FTIR even at the temperature of $1350^{\circ} \mathrm{C}$ which indicates HAP decomposition. HAP does not dehydrate completely before decomposition. We speculated that some oxyapatite (OAP) might be formed during dehydration with a great amount of OHAP still left in the system even up to the temperature of decomposition. In the temperature range of $1400-1500^{\circ} \mathrm{C}$, there was no significant difference in XRD patterns, only TTCP and $\alpha \mathrm{TCP}$ crystalline phases were observed. When the HAP gradually cools from $1500^{\circ} \mathrm{C}$, a part of TTCP and $\alpha$ TCP would directly reconstruct into OAP around $1350^{\circ} \mathrm{C}$. OAP existed in the temperature range of $1350-1300^{\circ} \mathrm{C}$ during cooling. When the temperature decreased to $1290^{\circ} \mathrm{C}$, a part of TTCP and $\alpha \mathrm{TCP}$ reconstructed into OHAP by rehydration reaction and OAP were rehydrated into OHAP as well. At $1100^{\circ} \mathrm{C}$, the rest of TTCP and $\alpha \mathrm{TCP}$ reconstitutes into HAP. As the temperature decreases, the OHAP is gradually rehydrated and reconstituted into HAP. (C) 1999 Elsevier Science Ltd. All rights reserved.
\end{abstract}

Keywords: Hydroxyapatite; Thermal behavior; Decomposition; Reconstruction

\section{Introduction}

Hydroxyapatite (HAP, $\left.\mathrm{Ca}_{10}\left(\mathrm{PO}_{4}\right)_{6}(\mathrm{OH})_{2}\right)$ has excellent biocompatiblity, promotes faster bone regeneration, and direct bonding to regenerated bone without intermediate connective tissue. It has been developed and is currently used in clinical applications [1-3]. In recent years, the plasma-spraying technique has been widely investigated as a means of improving the biocompatibility of metal materials in vivo, by adding a HAP coating onto the metal implant surface [4-6]. Deposition of HAP on a metal surface involves introducing HAP powder

\footnotetext{
* Corresponding author. Fax: 886-2-23940049.

E-mail address: double@ha.mc.ntu.edu.tw (F.-H. Lin)
}

into a high-temperature flame (usually over $10000^{\circ} \mathrm{C}$ ). These HAP particles are partly melted and may form a range of calcium phosphates including calcium oxide $(\mathrm{CaO})$ or amorphous calcium phosphate upon decomposition [5,7]. When the high-temperature particles are impacted onto the cold metal substrate (usually below $150^{\circ} \mathrm{C}$ ), the cooling rate of coatings can be as high as $10^{8 \circ} \mathrm{C} / \mathrm{s}$, which can lead to the formation of crystalline, noncrystalline and metastable crystalline products such as oxyhydroxyapatite (OHAP, $\left.\mathrm{Ca}_{10}\left(\mathrm{PO}_{4}\right)_{6}(\mathrm{OH})_{2-x} \mathrm{O}_{x} \square_{x}\right), \alpha-$ tricalcium phosphate $\left(\alpha \mathrm{TCP}, \mathrm{Ca}_{3}\left(\mathrm{PO}_{4}\right)_{2}\right)$, tetracalcium phosphate (TTCP, $\mathrm{Ca}_{4} \mathrm{P}_{2} \mathrm{O}_{9}$ ), calcium oxide $(\mathrm{CaO})$ and amorphous apatite in HAP coatings [8-10]. It has been reported that OHAP, TTCP and $\alpha \mathrm{TCP}$ have a greater tendency for dissolution and degradation than HAP in an aqueous environment [11], which will decrease chemical stability and enhance degradation of the coating in vivo. 
Recently, various plasma-spraying conditions and post-heat treatments have been studied for increasing the crystallinity of HAP coatings [8,12]. However, these HAP coatings contain numerous amorphous phases and complicated metastable phases, which made it difficult to elucidate the decomposition and reconstruction behavior of HAP coatings during the heat-treatment process. In the present paper we heated the commercial HAP powder from room temperature to $1500^{\circ} \mathrm{C}$ to investigate the thermal decomposition behavior of HAP in an air atmosphere. Additionally, the cooling rate of samples from $1500^{\circ} \mathrm{C}$ to room temperature were also controlled for exploring the reconstitution behavior of HAP during cooling. The XRD analysis was used to examine the phase transformation of HAP at different temperatures. The functional group change of HAP at different temperatures was observed by FTIR spectroscopy, and the
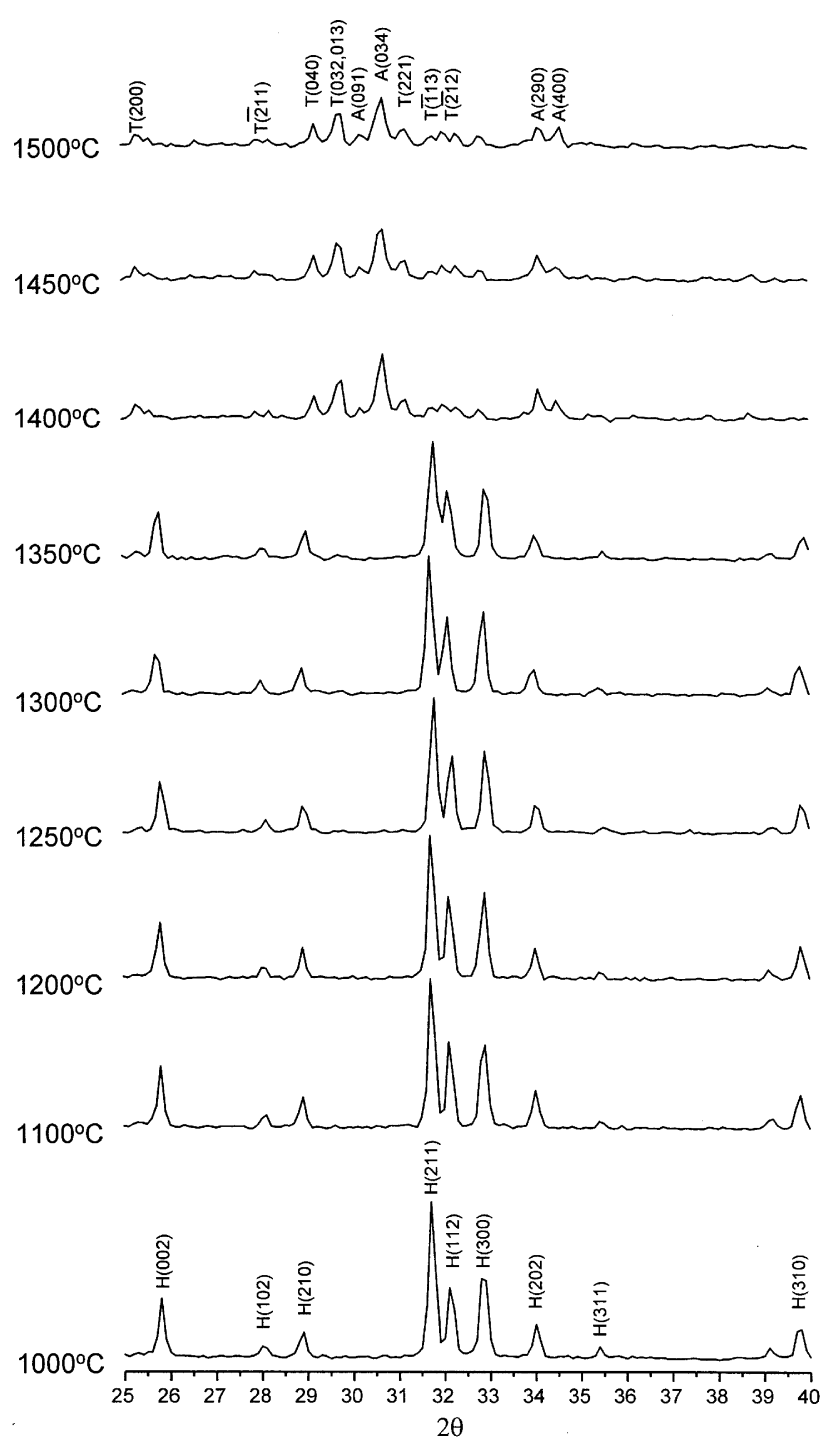

Fig. 1. X-ray diffraction patterns of HAP after heating to different temperatures (H : HAP, T : TTCP, A : $\alpha$ TCP). weight change of samples were recorded by TGA during heating and cooling.

\section{Materials and methods}

HAP powders were purchased from E. Merck (Darmstadt, Germany). It was placed in covered platinum crucibles and heated to different temperatures $\left(1000-1500^{\circ} \mathrm{C}\right)$ at a heating rate of $10^{\circ} \mathrm{C} / \mathrm{min}$ in an $\mathrm{SiC}$ heated furnace, and then maintained for $1 \mathrm{~h}$. After heating, the samples were quenched to room temperature. In addition, the reconstruction of HAP was also studied in this study. The HAP powders were heated to $1500^{\circ} \mathrm{C}$ and cooled to different temperatures at a cooling rate of $10^{\circ} \mathrm{C} / \mathrm{min}$. The samples then were maintained for $1 \mathrm{~h}$ and quenched to room temperature.

The crystalline phases of specimens were determined by a Rigaku (Denki Co. Ltd., Tokyo, Japan) X-ray powder diffractometer with $\mathrm{Cu} \mathrm{K} \alpha$ radiation and $\mathrm{Ni}$ filter. The scanning range of the samples was from 10 to $60^{\circ}$ with a scanning speed of $4^{\circ} / \mathrm{min}$. The infrared spectra were recorded using $\mathrm{KBr}$ pellets ( $1 \mathrm{mg}$ sample per $300 \mathrm{mg}$ $\mathrm{KBr}$ ) on a Jasco FTIR (JASCO FTIR 410, Tokyo, Japan) grating instrument with slow scan and 0.1 slit width. The wavelength of the FTIR used in the experiment was in the range of $4000-400 \mathrm{~cm}^{-1}$ to evaluate the functional group of the specimens. TA/SDT2960 (TA instruments, Inc. 109 Lukens Drive New Castle, DE 19720) was used to study the thermal behavior of the specimens. The scanning temperature for the thermal analysis of the specimens was from room temperature up to $1500^{\circ} \mathrm{C}$ with a heating rate of $10^{\circ} \mathrm{C} / \mathrm{min}$ and air flow rate of $90 \mathrm{ml} / \mathrm{min}$. The total weight of the specimen for each thermal analysis was $40 \mathrm{mg}$ and $\mathrm{Al}_{2} \mathrm{O}_{3}$ was as reference powder.

\section{Results}

\subsection{Crystal structure analysis}

Fig. 1 summarized the XRD patterns of HAP powder heated at the temperature of $1000-1500^{\circ} \mathrm{C}$. There was no significant difference in XRD patterns from 1000$1350^{\circ} \mathrm{C}$, it showed a stoichiometric hydroxyapatite characterized pattern (XRD JCPDS data file No. 9-432). At $1400^{\circ} \mathrm{C}$, the HAP was decomposed into TTCP and $\alpha \mathrm{TCP}$. There was no crystalline phase to be traced but TTCP and $\alpha \mathrm{TCP}$ in the temperature of $1400-1500^{\circ} \mathrm{C}$. Fig. 2 showed the results of XRD analysis of HAP powder cooling down from $1500^{\circ} \mathrm{C}$ with a cooling rate of $10^{\circ} \mathrm{C} / \mathrm{min}$. There was no phase transformation until a temperature of $1350^{\circ} \mathrm{C}$. Characteristic peaks of the reconstruction of HAP such as $(211)$ were burgeoned out on the XRD pattern at $1300^{\circ} \mathrm{C}$, the intensity 


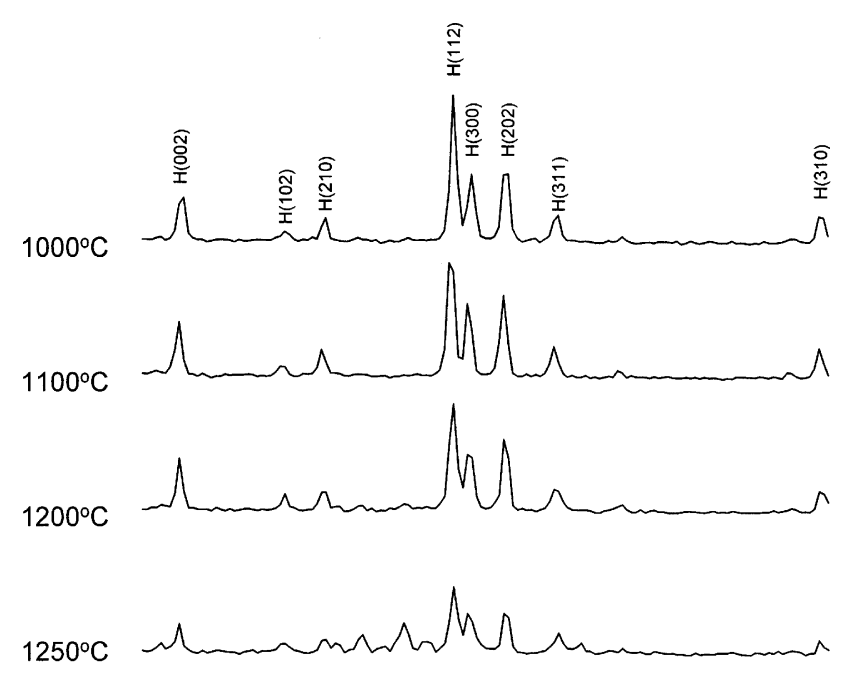

$1300^{\circ} \mathrm{C}$

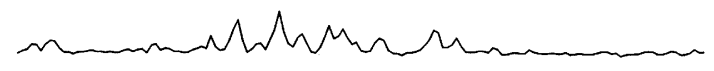

$1350^{\circ} \mathrm{C}$

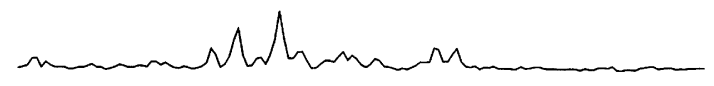

$1400^{\circ} \mathrm{C}$

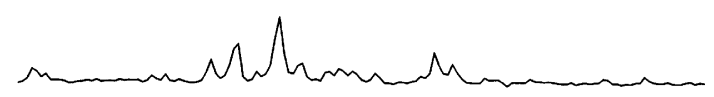

$1450^{\circ} \mathrm{C}$
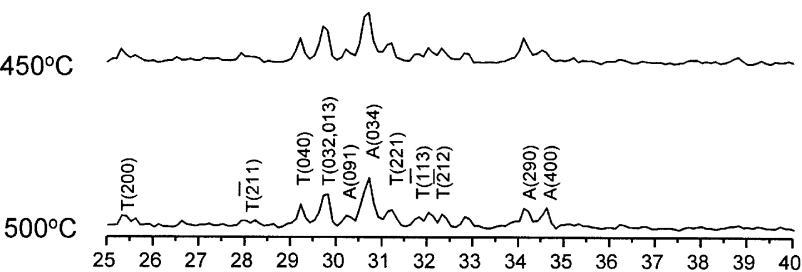

$2 \theta$

Fig. 2. X-ray diffraction patterns of HAP after cooling from $1500^{\circ} \mathrm{C}$ to the temperatures indicated (H : HAP, T : TTCP, A : $\alpha \mathrm{TCP})$.

gradually increasing with the temperature decrease. When the cooling down to $1100^{\circ} \mathrm{C}$, TTCP and $\alpha \mathrm{TCP}$ completely convert into HAP structure, where all the characterized peaks of TTCP and $\alpha \mathrm{TCP}$ disappear from the XRD pattern.

\subsection{FTIR spectrum analysis}

FTIR patterns of HAP heated at different temperatures are depicted in Fig. 3. At $1000^{\circ} \mathrm{C}$, it shows a typical FTIR spectrum of HAP. As the heating temperature increases, the librational and stretching band of $\mathrm{OH}^{-}$at 635 and $3572 \mathrm{~cm}^{-1}$ gradually decrease in their intensity and the bands at 945 and $1025 \mathrm{~cm}^{-1}$ corresponding to oxyhydroxyapatite functional group appear around $1200^{\circ} \mathrm{C}$. When the temperature is over $1300^{\circ} \mathrm{C}$, the libra-

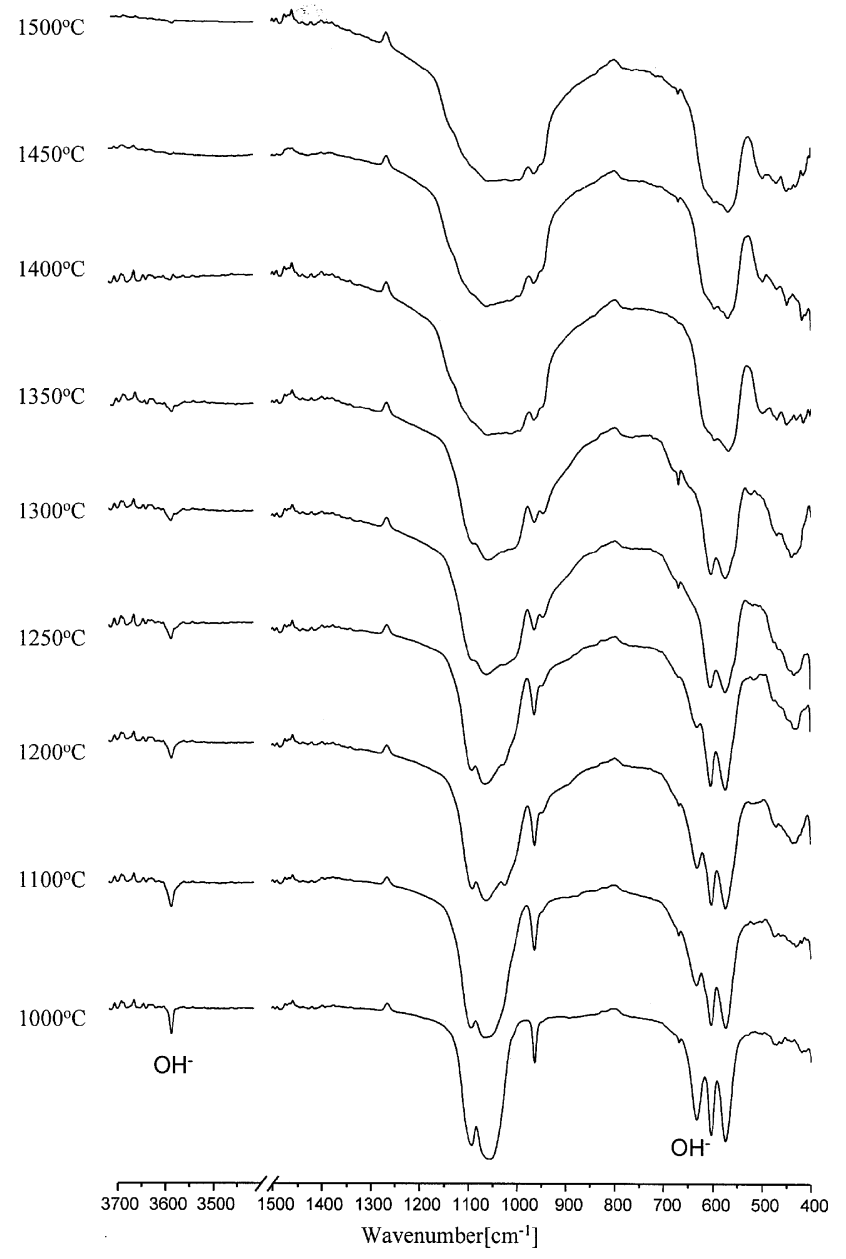

Fig. 3. FTIR spectra of HAP heated at different temperatures.

tional $\mathrm{OH}^{-}$bands disappear. The stretching band of $\mathrm{OH}^{-}$was still observed even at the temperature of $1350^{\circ} \mathrm{C}$. A broad band from 1200 to $950 \mathrm{~cm}^{-1}$ was formed when the temperature was increased up to $1400^{\circ} \mathrm{C}$, which corresponded to TTCP and $\alpha$ TCP. It was unchanged on increasing the temperature from 1400 to $1500^{\circ} \mathrm{C}$

Fig. 4 shows FTIR spectra of HAP powder at different temperatures, where $\mathrm{HAP}$ was cooled down from $1500^{\circ} \mathrm{C}$ with a cooling rate of $10^{\circ} \mathrm{C} / \mathrm{min}$. There was no significant change in the FTIR spectrum while the temperature cooling down from $1500-1350^{\circ} \mathrm{C}$. When the temperature down to $1300^{\circ} \mathrm{C}$, the broad band in the region of $1200-950 \mathrm{~cm}^{-1}$ for TTCP and $\alpha$ TCP would gradually narrow down. The stretching band of $\mathrm{OH}^{-}$at $3572 \mathrm{~cm}^{-1}$ could be traced by FTIR at $1250^{\circ} \mathrm{C}$, and the intensity increased with the decrease of temperature. The librational band of $\mathrm{OH}^{-}$at $635 \mathrm{~cm}^{-1}$ appeared at the temperature of $1200^{\circ} \mathrm{C}$ and the intensity would increase with the decrease of temperature. 


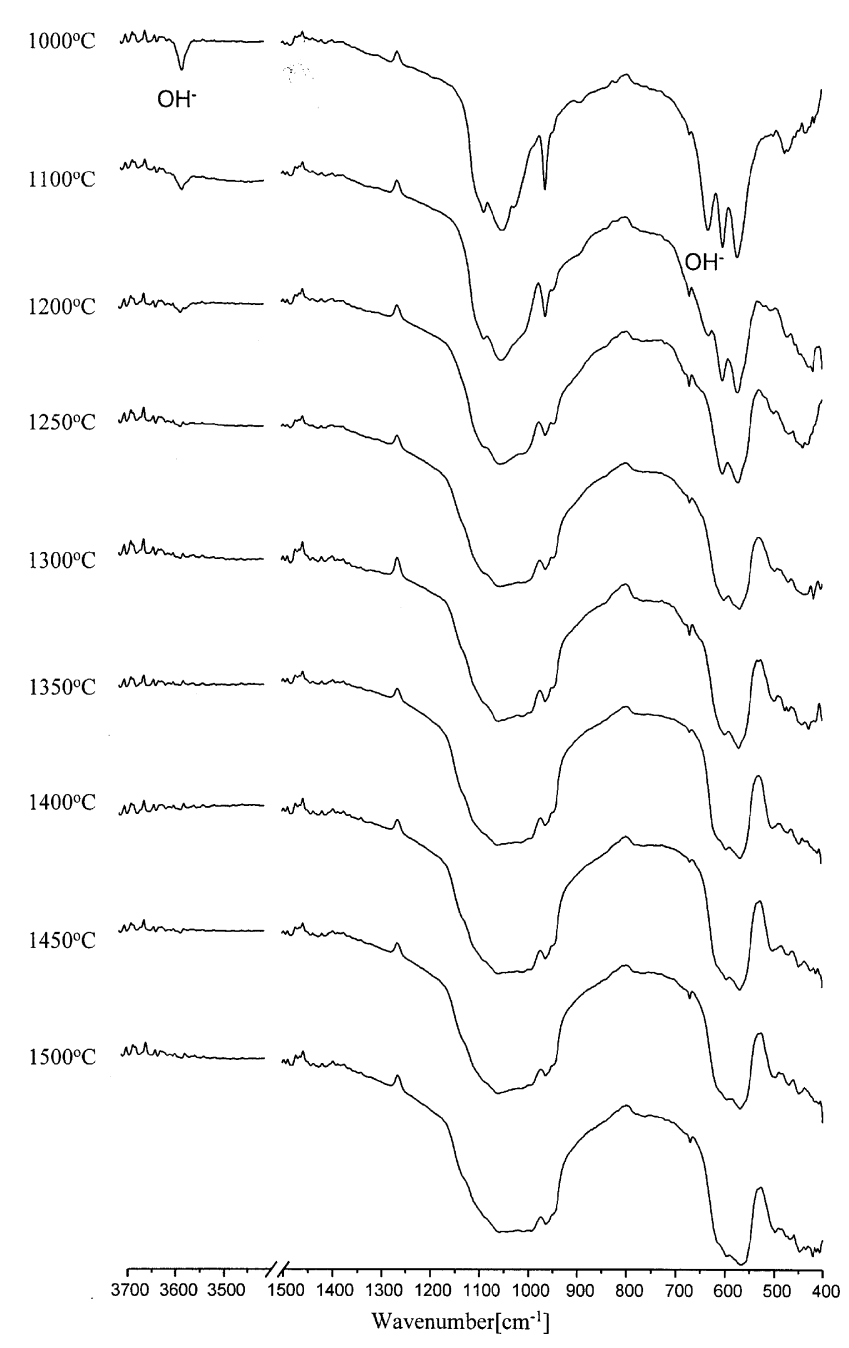

Fig. 4. FTIR spectra of HAP cooled from $1500^{\circ} \mathrm{C}$ to different temperatures.

\subsection{Thermogravimetric analysis}

Fig. 5 shows the thermogravimetric curve of HAP powder heated from room temperature to $1500^{\circ} \mathrm{C}$ and then cooled to room temperature. When the temperature is in the range of $100-400^{\circ} \mathrm{C}$, HAP powder quickly loses its weight. There is no apparent change in weight in the temperature range of $400-800^{\circ} \mathrm{C}$. The weight of HAP then slowly decreases with increasing temperature upto $800^{\circ} \mathrm{C}$. An inflection can be observed at $1360^{\circ} \mathrm{C}$ and a fast weight loss occurrs thereafter. On increasing the temperature up to $1400^{\circ} \mathrm{C}$, the weight of HAP slightly increases as the temperature rises. In the cooling curve, a small weight loss is recorded when the temperature cools down from 1500 to $1290^{\circ} \mathrm{C}$. The weight then quickly increases at the temperature of $1290-1240^{\circ} \mathrm{C}$. When the temperature cools down to $1240^{\circ} \mathrm{C}$, the weight gradually increases with a moderate rate. The weight is more or less constant once the temperature is below $900^{\circ} \mathrm{C}$.

\section{Discussion}

It has been reported that the structure of HAP heated at high temperature would be modified by many factors, including the synthesis methods and conditions, amount and type of impurities present, atmosphere of heating, additives, and other factors such as sample size, particle size, and heating rate of the sample $[2,3,14]$. As known, hydroxyapatite has two types of water in its structure-adsorbed and lattice water [15]. Adsorbed water - characterized reversibility, thermal instability from 25 to $200^{\circ} \mathrm{C}$, and weight loss without any effect on lattice parameters. Lattice water is irreversibly lost at the temperature of $200-400^{\circ} \mathrm{C}$, which causes a contraction in the $a$-lattice dimension during heating. At higher temperature, the hydroxyapatite gradually dehydrates, which lead to the release of $\mathrm{OH}^{-}$ions and then transforms to OHAP. OHAP has a large number of vacancies in its structure, a bivalent oxygen ion and a vacancy substitute for two monovalent $\mathrm{OH}^{-}$ions of HAP, which can be presented by a formula: $\mathrm{Ca}_{10}\left(\mathrm{PO}_{4}\right)_{6}(\mathrm{OH})_{2-2 x} \mathrm{O}_{x} \square_{x}$, where $\square$ stands for a vacancy. In the limit, when $x=1$, oxyapatite $\left(\mathrm{Ca}_{10}\left(\mathrm{PO}_{4}\right)_{6} \mathrm{O}\right.$, OAP $)$ is formed $[14,16,17]$. The HAP dehydration does not occur instantly but over a wide temperature range, which has been reported to mainly depend on the partial $\mathrm{H}_{2} \mathrm{O}$ pressure during heating. If performed under vacuum, HAP loses its $\mathrm{OH}^{-}$at a lower temperature, about $850^{\circ} \mathrm{C}$. If $\mathrm{HAP}$ is heated in $\mathrm{a}_{2} \mathrm{O}$ stream, the structure of HAP is then preserved up to $1100^{\circ} \mathrm{C}[13,14]$. It is generally denied for the existence of OAP, and moreover it is generally thought that the complete dehydration of HAP might cause lattice destruction, giving rise to a mixture of tricalcium phosphate and tetracalcium phosphate. Trombe and Montel [17] demonstrated the formation and existence of OAP by very rigidly controlled condition. It is particularly important to eliminate all traces of water when OAP is to be prepared. The range of temperature for OAP stability is very narrow around $800-1050^{\circ} \mathrm{C}$.

In this study, it is difficult to observe HAP transformation to OHAP by XRD because most of the characteristic peaks of the two compounds overlap one another. The presence of OHAP in HAP can, however, be detected by FTIR. HAP has two types of $\mathrm{OH}$ band- $-\mathrm{OH}$ stretching and librational absorption bands at 3572 and $630 \mathrm{~cm}^{-1}$, respectively. As shown in Fig. 3, the intensity of the peak at $630 \mathrm{~cm}^{-1}$, which corresponds to the $\mathrm{OH}^{-}$ librational mode diminishes with a temperature increase until $1300^{\circ} \mathrm{C}$ where it is no longer distinguishable from the background. The $\mathrm{OH}^{-}$stretching mode at $3572 \mathrm{~cm}^{-1}$ also decreased with the increase of temperature. The $\mathrm{OH}^{-}$stretching band seems more stabilized than the $\mathrm{OH}^{-}$librational mode at higher temperatures. The $\mathrm{OH}^{-}$stretching band could be detected in the FTIR curve even at a temperature up to $1350^{\circ} \mathrm{C}$. The $\mathrm{OH}^{-}$ librational $630 \mathrm{~cm}^{-1}$ mode is missing in the biological 


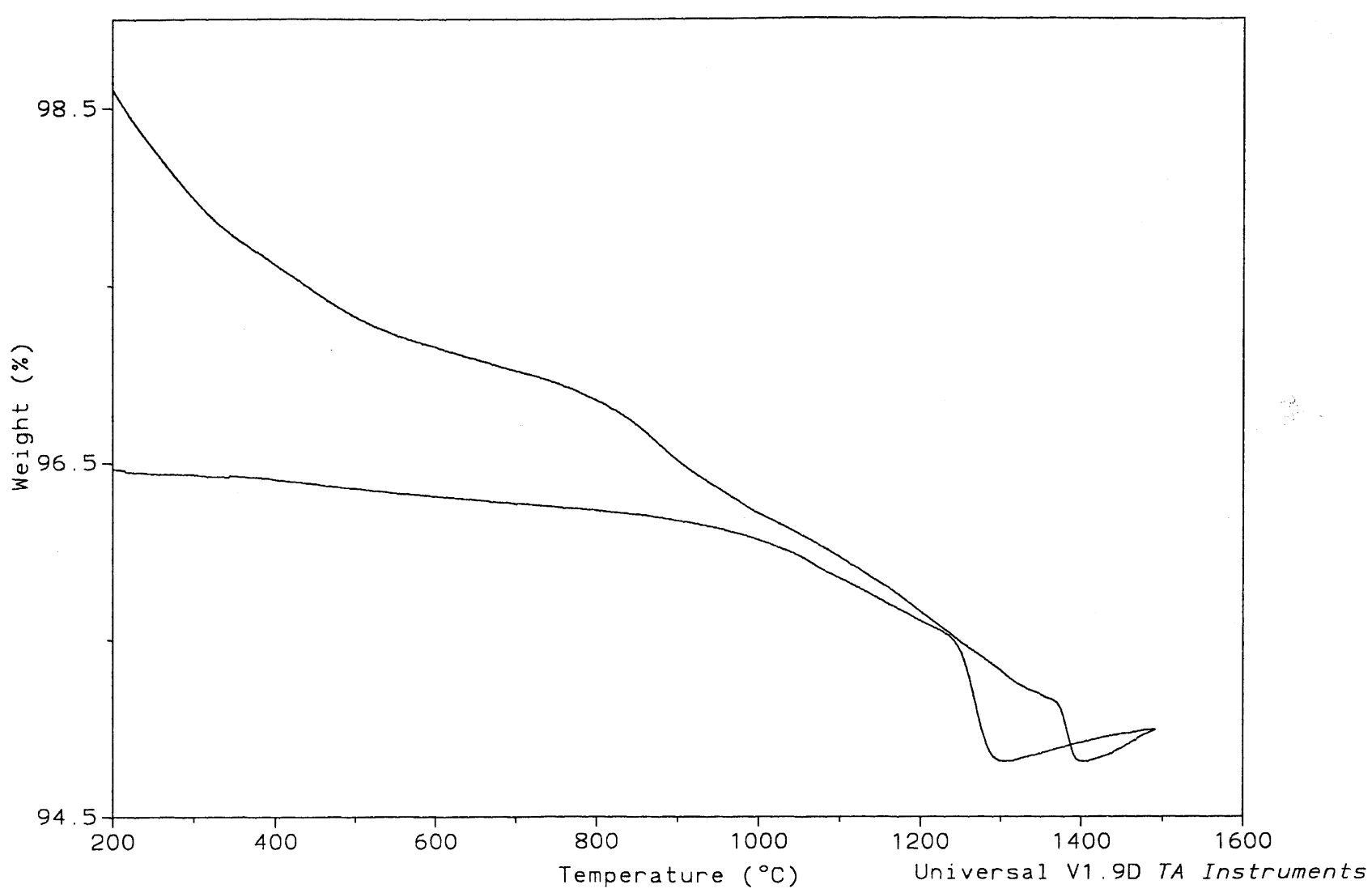

Fig. 5. TGA results of HAP heated from 200 to $1500^{\circ} \mathrm{C}$ and then cooled to $200^{\circ} \mathrm{C}$.

apatite pattern, but present in the synthetic HAP pattern, although $\mathrm{OH}$ is present in both materials. The space group of biological HAP (non-stoichiometric hydroxyapatite) has been determined by X-ray diffraction methods to be $\mathrm{P} 6_{3} / \mathrm{m}$. However, theoretical considerations suggest the space group of synthetic HAP (stoichiometric hydroxyapatite) should be $\mathrm{P}_{3}$. It has been proposed that the hydroxyl ions in HAP are displaced by some $0.3 \AA$ along the hexagonal screw axis, destroying the mirror plane and consequently altering the space group from $\mathrm{P} 6_{3} / \mathrm{m}$ to $\mathrm{P} 6_{3}$. The absence of the $\mathrm{OH}^{-}$librational $630 \mathrm{~cm}^{-1}$ mode during heating is the result of stoichiometric HAP changing to non-stoichiometric HAP.

Fig. 5 shows the TGA curve of HAP, a continuous curve with a weight loss at the temperature from 800 to $1360^{\circ} \mathrm{C}$. When the temperature reaches $1360^{\circ} \mathrm{C}$, a significant weight loss appears which extends over the temperature region of $1360-1400^{\circ} \mathrm{C}$. According to the equilibrium phase diagram of $\mathrm{CaO} / \mathrm{P}_{2} \mathrm{O}_{5}$, HAP will decompose into TTCP and $\alpha \mathrm{TCP}$ at $1350^{\circ} \mathrm{C}$ [18]. From the XRD results (Fig. 1), the decomposition of HAP to TTCP and $\alpha$ TCP at $1350-1400^{\circ} \mathrm{C}$ with a significant weight change (approximately $0.75 \mathrm{wt} \%$ ) attributed to dehydration. But the $\mathrm{OH}^{-}$stretching mode of HAP still appeared at $1350^{\circ} \mathrm{C}$ (Fig. 3) - the commencement HAP decomposition. It indicated that the HAP did not dehydrate completely before decomposition. We speculated that some of the OAP might be formed during dehydration and there was a great amount of OHAP remaining in the system even up to the temperature of decomposition. According to the reaction, OAP decomposed into TTCP and $\alpha$ TCP:

$$
\mathrm{Ca}_{10}\left(\mathrm{PO}_{4}\right)_{6} \mathrm{O} \rightarrow 2 \mathrm{Ca}_{3}\left(\mathrm{PO}_{4}\right)_{2}+\mathrm{Ca}_{4} \mathrm{P}_{2} \mathrm{O}_{9}
$$

and does not involve any change in weight.

From the XRD analysis (Fig. 1), only TTCP and $\alpha$ TCP appeared after HAP decomposition. There was no significant difference in XRD patterns at the temperature of $1400-1500^{\circ} \mathrm{C}$. Some investigators reported that the calcium phosphates such as $\mathrm{Ca}_{2} \mathrm{P}_{2} \mathrm{O}_{7}$ and $\mathrm{CaO}$, could be observed during HAP decomposition. These reactions were described as follows [19]:

$2 \mathrm{Ca}_{10}\left(\mathrm{PO}_{4}\right)_{6} \mathrm{O} \rightarrow 2 \mathrm{Ca}_{3}\left(\mathrm{PO}_{4}\right)_{2}+\mathrm{Ca}_{2} \mathrm{P}_{2} \mathrm{O}_{7}+3 \mathrm{Ca}_{4} \mathrm{P}_{2} \mathrm{O}_{9}$

or

$$
\mathrm{Ca}_{10}\left(\mathrm{PO}_{4}\right)_{6}(\mathrm{OH})_{2} \rightarrow 3 \mathrm{Ca}_{3}\left(\mathrm{PO}_{4}\right)_{2}+\mathrm{CaO}+\mathrm{H}_{2} \mathrm{O} .
$$


In the present study, no other crystalline phases could be detected other than TTCP and $\alpha$ TCP at the temperature of $1400-1500^{\circ} \mathrm{C}$. According to the phase diagram of $\mathrm{CaO} / \mathrm{P}_{2} \mathrm{O}_{5}$ and the study of the thermal decomposition reaction of $\mathrm{HAP}$, it is impossible that $\mathrm{Ca}_{2} \mathrm{P}_{2} \mathrm{O}_{7}, \mathrm{CaO}$ and $\mathrm{P}_{2} \mathrm{O}_{5}$ will appear in the system. $\mathrm{CaO}$ and $\mathrm{Ca}_{2} \mathrm{P}_{2} \mathrm{O}_{7}$ could be traced only in non-equilibrium conditions such as a sudden temperature increase or decrease, typical of the thermal spray or plasma spray process.

It is known that TTCP and $\alpha$ TCP could reconstitute into HAP during cooling. The reconstitution temperature of HAP has been reported to be dependent on cooling rate and atmosphere $[12,13]$. The cooling rate of high-temperature molten HAP particles deposited on a cold metal substrate by the plasma-spraying technique could be as high as $10^{8 \circ} \mathrm{C} / \mathrm{s}$, which led to a large amount of TTCP and $\alpha \mathrm{TCP}$ on the substrate where a small amount of $\mathrm{CaO}$ and $\mathrm{Ca}_{2} \mathrm{P}_{2} \mathrm{O}_{7}$ could also be traced. McPherson et al. [20] reheated HAP coatings in air at $600^{\circ} \mathrm{C}$ that resulted in recrystallization of the glass phase and formation of HAP with water vapor. de Groot et al. [21] thought that TTCP and $\alpha \mathrm{TCP}$ are more stable than HAP in dry atmosphere, which is difficult to convert into HAP in vacuum. Chen et al. [12] studied the effect of increasing the crystallinity of HAP coatings by post-heat treatment and found that TTCP and $\alpha \mathrm{TCP}$ could convert to HAP by reactions of hydration in a humid atmosphere. They suggested that TTCP and $\alpha \mathrm{TCP}$ could covert into HAP by the reactions of hydration:

$3 \mathrm{Ca}_{4} \mathrm{P}_{2} \mathrm{O}_{9}+3 \mathrm{H}_{2} \mathrm{O} \rightarrow \mathrm{Ca}_{10}\left(\mathrm{PO}_{4}\right)_{6}(\mathrm{OH})_{2}+2 \mathrm{Ca}(\mathrm{OH})_{2}$

and

$10 \mathrm{Ca}_{3}\left(\mathrm{PO}_{4}\right)_{2}+6 \mathrm{H}_{2} \mathrm{O} \rightarrow 3 \mathrm{Ca}_{10}\left(\mathrm{PO}_{4}\right)_{6}(\mathrm{OH})_{2}+2 \mathrm{H}_{3} \mathrm{PO}_{4}$.

As Eqs. (4) and (5), TTCP and $\alpha$ TCP would reconstruct into HAP by a series of hydration reactions, which would catch $\mathrm{OH}^{-}$ions back into the HAP lattice and lead to weight increase. In our study, there was no significant weight change to be recorded in TGA and no $\mathrm{OH}^{-}$ bands (stretching or librational mode) to be traced in FTIR analysis during cooling from $1500-1300^{\circ} \mathrm{C}$ (Fig. 4). The HAP peaks appeared in the XRD pattern once the temperature reached $1300^{\circ} \mathrm{C}$, Fig. 2. It seemed that the TTCP and $\alpha$ TCP were directly converted into OAP as the following reaction with no weight change involved

$2 \mathrm{Ca}_{3}\left(\mathrm{PO}_{4}\right)_{2}+\mathrm{Ca}_{4} \mathrm{P}_{2} \mathrm{O}_{9} \rightarrow \mathrm{Ca}_{10}\left(\mathrm{PO}_{4}\right)_{6} \mathrm{O}$.

Water vapor or $\mathrm{OH}^{-}$ions were not involved at the beginning of the reconstruction reaction of HAP. This transformation occurs without a phase change. OAP seems existent in this system during cooling. Trombe et al. [17] reported that the OAP is a highly unstable structure, which does not exist at temperatures lower than $800^{\circ} \mathrm{C}$ (under $10^{-4}-10^{-6}$ Torr). They found that a small weight increase occurs during cooling of OAP from $1000^{\circ} \mathrm{C}$ to room temperature, which represents partial rehydration upon cooling to $800^{\circ} \mathrm{C}$. In the study, the stability range of OAP was very narrow, approximately $1350-1300^{\circ} \mathrm{C}$. As the temperature decreased, OAP would be rehydrated into OHAP. A significant weight increase was recorded by TGA in the temperature range of $1290-1240^{\circ} \mathrm{C}$. In the temperature range of $1290-1240^{\circ} \mathrm{C}$, the characterized peaks of HAP could be observed obviously and the intensity of the peaks increased as the temperature decreased. FTIR results (Fig. 4) showed that only a slight $\mathrm{OH}^{-}$stretching band (at $3572 \mathrm{~cm}^{-1}$ ) was present at $1250^{\circ} \mathrm{C}$. While at $1200^{\circ} \mathrm{C}$, the intensity of $\mathrm{OH}^{-}$ bands could be observed more clearly. It is postulated that TTCP and $\alpha$ TCP can gradually convert into OAP, and then form OHAP with an uptake of $\mathrm{OH}^{-}$ions at $1290-1240^{\circ} \mathrm{C}$. TTCP and $\alpha$ TCP would completely disappear at $1100^{\circ} \mathrm{C}$ as $\mathrm{OH}^{-}$bands of HAP are detected in the FTIR spectrum. As the temperature further decreases, OHAP gradually rehydrates and reconstitutes into HAP.

\section{Conclusions}

In this study, HAP was heated from room temperature to $1500^{\circ} \mathrm{C}$ in an air atmosphere. It would gradually release $\mathrm{OH}^{-}$ions and transform to OHAP around $1000-1360^{\circ} \mathrm{C}$. Above $1360^{\circ} \mathrm{C}$, the OHAP would decompose into TTCP and $\alpha \mathrm{TCP}$. The $\mathrm{OH}^{-}$stretching bands of HAP could be detected at $1350^{\circ} \mathrm{C}$, the commencement of HAP decomposition. It indicated that the HAP did not dehydrate completely before being decomposed. We speculated that some OAP might be formed during dehydration and there was a great amount of OHAP still left in the system even up to decomposition temperature. From 1400 to $1500^{\circ} \mathrm{C}$, there were no significant difference in XRD patterns, only TTCP and $\alpha$ TCP could be observed. We thought that the thermal decomposition of HAP was through the following phase transformations: HAP $\rightarrow$ HAP + OHAP (transform from part of HAP) $\rightarrow$ HAP + OHAP + OAP (transform from part of OHAP) $\rightarrow$ TTCP $+\alpha$ TCP.

When HAP was heated to $1500^{\circ} \mathrm{C}$ and then cooled at a rate of $10^{\circ} \mathrm{C} / \mathrm{min}$, a part of TTCP and $\alpha \mathrm{TCP}$ reconstructed into $\mathrm{OAP}$ at $1350^{\circ} \mathrm{C}$ because no $\mathrm{OH}^{-}$stretching bands were traced and no weight increase was recorded. We could detect TTCP and $\alpha$ TCP in the XRD pattern at $1100^{\circ} \mathrm{C}$. It reflected that a part of TTCP and $\alpha \mathrm{TCP}$ initially converted into OAP around $1350^{\circ} \mathrm{C}$ and then exist in the temperature range of $1350-1300^{\circ} \mathrm{C}$ during cooling. When cooling to $1290^{\circ} \mathrm{C}$, a part of TTCP and $\alpha \mathrm{TCP}$ convert into OHAP by rehydration. At $1100^{\circ} \mathrm{C}$, the rest of TTCP and $\alpha$ TCP completely reconstitute the HAP phase. OHAP then gradually rehydrates and reconstitutes HAP as the temperature decrease. We believe 
that the phase transformation of HAP down from $1500^{\circ} \mathrm{C}$ should be through the following steps: [TTCP/ $\alpha \mathrm{TCP}] \rightarrow[\mathrm{TTCP} / \alpha \mathrm{TCP}]+\mathrm{OAP}$ (transform from part of $\left.[\mathrm{TTCP} / \alpha \mathrm{TCP}], 1350-1300^{\circ} \mathrm{C}\right) \rightarrow[\mathrm{TTCP} / \alpha \mathrm{TCP}]+$ OHAP (transform from OAP and part of [TTCP/ $\left.\alpha \mathrm{TCP}], 1290-1240^{\circ} \mathrm{C}\right) \rightarrow[\mathrm{TTCP} / \alpha \mathrm{TCP}]+\mathrm{OHAP}+$ HAP (convert from [TTCP $/ \alpha \mathrm{TCP}]$ and OHAP, 1240$1100^{\circ} \mathrm{C}$ ) $\rightarrow$ HAP (below $1100^{\circ} \mathrm{C}$ ).

\section{Acknowledgements}

The authors are grateful for the financial support from the National Science Council. The enthusiasm and knowledge of my colleagues inspired many improvements in this study. We would like to thank those who contributed to the project.

\section{References}

[1] Jarcho M. Calcium phosphate ceramics as hard tissue prosthetics. Clin Orthop Rel Res 1981;157:259-78.

[2] Aoki H. Medical application of hydroxyapatite. Tokyo: Ishiyaku Euro America Inc., St. Louis: Takayama Press, 1994.

[3] de Groot K. Bioceramics of calcium phosphate. Boca Raton, FL: CRC Press Inc., 1983.

[4] Ducheyne P, Radin SR, Heughebaert M, Heughebaert JC. Calcium phosphate ceramic coatings on porous titanium: effect of structure and composition on electrophoretic deposition, vacuum sintering and in vitro dissolution. Biomaterials 1990; 11:224-54.

[5] Koch B, Wolke JGC, de Groot K. X-ray diffraction studies on plasma-sprayed calcium phosphate-coated implants. J Biomed Mater Res 1990;24:665-7.

[6] Ellies LG, Nelson DG, Featherstone JD. Crystallographic changes in calcium phosphates during plasma-spraying. Biomaterials 1992;13:313-6.
[7] Weng J, Liu X, Zhang X, Ma Z, Ji X, Zyman Z. Further studies on the plasma-sprayed amporphous phase in hydroxyapatite coatings and its deamorphization. Biomaterials 1993;14:578-82.

[8] Zyman Z, Weng J, Liu X, Li X, Zhang X. Phase and structural changes in hydroxyapatite coatings under heat treatment. Biomaterials 1994;15:151-5.

[9] Gross KA, Berndt CC, Herman H. Amorphous formation in plasma-sprayed hydroxyapatite coatings. J Biomed Mater Res 1998;39:407-14.

[10] Gross KA, Berndt CC. Thermal processing of hydroxyapatite for coating production. J Biomed Mater Res 1998;39:580-7.

[11] Radin SR, Ducheyne P. The effect of calcium phosphate ceramic composition and structure on in vitro behavior. I. Dissolution. J Biomed Mater Res 1993;27:25-34.

[12] Chen J, Tong W, Yang C, Feng J, Zhang X. Effect of atmosphere on phase transformation in plasma-sprayed hydroxyapatite coatings during heat treatment. J Biomed Mater Res 1997;34:15-20.

[13] Locardi B, Pazzaglia UE, Gabbi C, Profilo B. Thermal behaviour of hydroxyapatite intended for medical applications. Biomaterials 1993;14:437-41.

[14] Ducheyne P, Hastings GW. Metal ceramic biomaterials, vol. II: strength and surface. Boca Raton, FL: CRC Press, 1984.

[15] LeGeros RZ, Bonel G, Legros R. Types of $\mathrm{H}_{2} \mathrm{O}$ in human enamel and in precipitated apatites. Calcif Tiss Res 1978;26:111-8.

[16] Wang PE, Chaki TK. Sintering behaviour and mechanical properties of hydroxyapatite and dicalcium phosphate. J Mater Sci Mater Med 1993;4:150-8.

[17] Trombe JC, Montel G. Some features of the incorporation of oxygen in different oxidation states in the apatitic lattice-I. J Inorg Nucl Chem 1977;40:15-21.

[18] Riboud PV. Composition and stability of apatites in the system CaO- $\mathrm{P}_{2} \mathrm{O}_{5}$-iron oxide- $\mathrm{H}_{2} \mathrm{O}$ at high temperature. Ann Chim 1973;8:381-90.

[19] Jiming Z, Zhang C, Xingdong Z, Jiyong S, de Groot K. High temperature characteristics of synthetic hydroxyapatite. J Mater Sci Mater Med 1993;4:83-5.

[20] McPherson R, Gane N, Bastow TJ. Structural characterization of plasma-sprayed hydroxylapatite coatings. J Mater Sci Mater Med 1995;6:327-34

[21] de Groot K, Klein CPAT, Wolke JGC, de Blieck-Hogervorst JMA Chemistry of calcium phosphate bioceramics. In: Yamamuro T, Hench L, Wilson J, editors. CRC handbook of bioactive ceramics, vol. II. Boca Raton, FL: CRC press, 1990. p. 3-16. 